\title{
A Case of Malaria Patient with SARS-CoV-2 Antibody False-Positive
}

hong zhou ( $\nabla$ yan913461@163.com )

Suining Central Hospital

\section{Case report}

Keywords: SARS-CoV-2 antibody, COVID-19, malaria

Posted Date: August 6th, 2021

DOI: https://doi.org/10.21203/rs.3.rs-773536/v1

License: (c) (i) This work is licensed under a Creative Commons Attribution 4.0 International License. Read Full License 


\section{Abstract}

Background: The SARS-CoV-2 antibody detection are used to diagnose or exclude suspected COVID-19 patients as a supplement to nucleic acid detection. False-positive results of SARS-CoV-2 antibody have been reported but rarely associated with malaria. A case of malaria patient with SARS-CoV-2 antibody false-positive is described.

Case presentation: A 24 year-old male returned from Côte d'Ivoire was diagnosed Plasmodium falciparum by Malaria rapid diagnostic test. The patient had suspicious exposure to COVID-19. His SARS-CoV-2 IgM antibody was positive one day before admission and turned negative on the 18th day of admission, while the IgG antibody and nasopharyngeal swabs SARS-Cov-2 nucleic acid had been negative.

Conclusion: Malaria might cause false positive for SARS-CoV-2 IgM antibody. A careful interpretation of the SARS-CoV-2 antibody result is useful to avoid wasting medical resources especially malaria-endemic areas.

\section{Background}

Early and rapid diagnosis is essential to control the corona virus disease-19 (COVID-19) epidemic. The SARS-CoV-2 IgM and IgG antibody detection are used to diagnose or exclude suspected patients as a supplement to nucleic acid detection ${ }^{[1]}$. Due to the lack of numerous clinical sample evaluations, the SARS-Cov-2 antibody detection kit on the market needs to further confirm the accuracy and validity. Some studies have reported that SARS-Cov-2 antibodies may exist false-positive results, but rare reports in malaria patients.

A case of malaria patient with SARS-CoV-2 antibody false-positive is reported. The aim of this case report is to describe the availability of SARS-CoV-2 antibody for identifying COVID-19 in malaria patients.

\section{Case Presentation}

A 24-year-old male patient developed muscle soreness, nasal congestion and sore throat, without fever and respiratory symptoms on September 7, 2020. He was hospitalized in the Infectious Diseases Department of Suining Central Hospital from September 10 to September 28, 2020.

The epidemiological history of this patient was investigated (Fig. 1). From May 2019 to work in Côte d'Ivoire, Africa, the patient has not been in contact with COVID-19 patients. On August 10, 2020, he postponed his return to China because of fever. He flew from Côte d'Ivoire and transferred in Paris to Guangzhou from August 24 to 26, 2020. On the plane, 3 passengers were diagnosed with COVID-19, and their seats were more than 3 meters away from the patient's. The patient was isolated in Guangzhou UniPresident Hotel for 14 days after the SARS-CoV-2 nucleic acid and antibody were negative at entry. During isolation, he had 3 times SARS-CoV-2 nucleic acid negative. 
Laboratory results showed white blood cell $\left(8.4 \times 10^{\wedge} 9 / \mathrm{L}\right)$, neutrophil $\left(4.56 \times 10^{\wedge} 9 / \mathrm{L}\right)$, lymphocyte $\left(2.84 \times 10^{\wedge} 9 / \mathrm{L}\right)$, reticulocytes $(2.1-5.7 \%)$. Chest CT was normal. SARS-Cov-2 nucleic acid and antibody were tested. Detection of SARS-CoV-2 nucleic acid uses real-time reverse transcription-polymerase chain reaction (RT-PCR). SARS-Cov-2 IgM and IgG antibodies detection use rapid diagnostic tests (colloidal gold method, Zhuhai Livzon Diagnostics, Inc. Test Principle is showed in Fig. 2). Malaria diagnosis relies on rapid diagnostic test (RDT, Guangzhou Wondfo Biotech Co.,Ltd. Test Principle is showed in Fig. 3.) and microscopy.

Refer to Table 1 for the results of SARS-Cov-2 IgM and IgG antibodies, SARS-Cov-2 nucleic acids, malaria rapid diagnostic test and microspic exarmnation of blood films. The SARS-Cov-2 IgM antibody has been tested positive many times and turned negative after 18 days, while the IgG antibody and nasopharyngeal swabs SARS-Cov-2 nucleic acid have been negative. Malaria rapid diagnostic test suggested P. falciparum infection. Plasmodium blood films tested negative multiple times. 
Table 1

Inspection of SARS-Cov-2 and Plasmodium infection

\begin{tabular}{|c|c|c|c|c|c|c|}
\hline & \multicolumn{2}{|c|}{$\begin{array}{l}\text { SARS-Cov-2 } \\
\text { antibody }\end{array}$} & \multicolumn{2}{|c|}{ SARS-Cov-2 nucleic acids } & \multicolumn{2}{|c|}{ Malaria parasites } \\
\hline & $\lg M$ & IgG & $\begin{array}{l}\text { Nasopharyngeal } \\
\text { swab }\end{array}$ & $\begin{array}{l}\text { Rectal } \\
\text { swab }\end{array}$ & RDT & $\begin{array}{l}\text { Microspic exarmnation of } \\
\text { blood films }\end{array}$ \\
\hline $\begin{array}{l}\text { Aug 07, } \\
2020\end{array}$ & & & - & & & \\
\hline $\begin{array}{l}\text { Aug 26, } \\
2020\end{array}$ & - & - & - & & & \\
\hline $\begin{array}{l}\text { Sep 04, } \\
2020\end{array}$ & & & - & & & \\
\hline $\begin{array}{l}\text { Sep 08, } \\
2020\end{array}$ & & & - & & & \\
\hline $\begin{array}{l}\text { Sep 09, } \\
2020\end{array}$ & + & - & & & $\begin{array}{l}\text { T1 } \\
+\end{array}$ & - \\
\hline $\begin{array}{l}\text { Sep 10, } \\
2020\end{array}$ & + & - & - & & $\begin{array}{l}\mathrm{T} 1 \\
+\end{array}$ & - \\
\hline $\begin{array}{l}\text { Sep 11, } \\
2020\end{array}$ & & & - & & & \\
\hline $\begin{array}{l}\text { Sep 12, } \\
2020\end{array}$ & + & - & - & & & \\
\hline $\begin{array}{l}\text { Sep 16, } \\
2020\end{array}$ & + & - & - & - & $\begin{array}{l}\text { T1 } \\
+\end{array}$ & - \\
\hline $\begin{array}{l}\text { Sep 18, } \\
2020\end{array}$ & + & - & - & & & \\
\hline $\begin{array}{l}\text { Sep 23, } \\
2020\end{array}$ & \pm & - & - & - & $\begin{array}{l}\text { T1 } \\
+\end{array}$ & - \\
\hline $\begin{array}{l}\text { Sep 27, } \\
2020\end{array}$ & - & - & - & - & & \\
\hline
\end{tabular}

The patient was diagnosed P. falciparum by Malaria rapid diagnostic test. He was treated with artesunate for 3 days (September 10 to 12, 2020), sequential dihydroartemisinin and piperaquine phospate tablets for 2 days (September 13 to 14,2020 ).

\section{Discussion}

SARS-Cov-2 enters the body to cause an immune response, with IgM antibody appearing first, and then IgG antibody. After the appearance of IgG antibody, the concentration will continue to increase, and the 
IgM antibody will continue to decrease until it disappears. IgG antibody will exist for a long time. By monitoring the dynamic changes of IgM and IgG antibody, it is helpful to diagnose the SARS-Cov-2 infection and judge the infection status. IgM antibody is produced by the body's initial immune response, with fast production speed and short duration, as indicator of early infection; IgG antibody is produced later than IgM and has a long duration, and can be used as indicator of infection and previous infection.

Studies have shown that after SARS-Cov-2 infects the body, antibodies can be detected usually in 5 to 10 days ${ }^{[2]}$. Guo $L$ et ${ }^{[3]}$ research showed SARS-Cov-2 specific IgM antibodies were detected at 5 days (interquartile range [IQR], 3 to 6 days) after onset, while IgG antibodies appeared at 14 days (IQR, 10-18 days). Zhao $\mathrm{J}$ et ${ }^{[4]}$ found over $90 \%$ of patients were seropositive for IgG antibodies after day 14 of illness. Our study showed that IgM antibody was persistent positive for 18 days, while IgG antibody and SARS-Cov-2 nucleic acid continue to be negative, so IgM antibody was judged to be false positive.

Currently, specific antibody (IgM, IgG) detection tests mainly include colloidal gold method (lateral flow immunoassays, LFIA), enzyme-linked immunosorbent assays (ELISAs), chemiluminescence immunoassays, etc ${ }^{[5]}$. Some studies have reported false positives of SARS-Cov-2 antibodies ${ }^{[6,7]}$. The reasons are related to the following: different test kits used by various testing institutions, different settings of the positive cut-off value of the test kits, different testing instruments, differences in the level of operators, and patients situation and so on ${ }^{[8]}$.

The colloidal gold method is a rapid diagnostic test based on the principle of using colloidal gold as a tracer for immunoassay. The operation of the colloidal gold method is simple, and the qualitative analysis of $\operatorname{lgM}$ and $\lg G$ antibodies can be performed without additional equipment ${ }^{[9]}$, moreover the positive or negative result can be judged by visual observation without the positive cut-off value. However, SARS-Cov-2 antibody test may have false positive results due to the presence of some interfering substances in clinical samples. Interfering substances include endogenous substances and exogenous substances. Endogenous substances include: rheumatoid factor, heterophile antibodies, complement, anti-mouse Ig antibodies induced by the use of murine antibodies for treatment or diagnosis, and lysozyme, etc ${ }^{[6,8,10]}$. Exogenous substances include: specimen hemolysis, specimen storage time is too long, etc ${ }^{[8]}$. Yadouleton A et al. ${ }^{[11]}$ used ELISAs to test COVID-19 $\operatorname{cases}(\mathrm{n}=8)$ and fever of unknown origin cases (as prepandemic controls, $n=60$ ). They found $<25 \%$ false-positive results likely due to unspecific immune responses elicited by acute malaria. The higher proportion of SARS-CoV-2 false-positive in acute malaria patients compared with likely subacute or chronic malaria patients. In our case, we also considered that malaria caused a non-specific immune response leading to false positive for SARS-CoV-2 IgM antibody.

\section{Conclusion}

SARS-CoV-2 antibody test may be useful for diagnosis, risk management and mitigating transmission. However, false-positive results lead to unnecessary quarantine and resource allocation. So in a malaria- 
endemic area, the results of the SARS-CoV-2 antibodies need to be interpreted carefully to avoid wasting medical resources and implementing unnecessary infection control interventions.

\section{Declarations}

\section{Acknowledgements}

None.

\section{Authors' contributions}

$\mathrm{HZ}$ collected and analyzed the data. $\mathrm{HZ}$ was responsible for writing the article, and approved the final manuscript.

\section{Funding}

This research did not receive any specifc grant from funding agencies in the public, commercial, or notfor-proft sectors.

\section{Availability of data and materials}

The datasets used and analyzed during the current study are available from the corresponding author in reasonable request.

\section{Declarations}

\section{Ethics approval and consent to participate}

The study was approved by the Ethical Committee of Suining Central Hospital.

\section{Consent for publication}

Written informed consent was obtained from the patient for publication of this case report .

\section{Competing interests}

No potential conflicts of interest relevant to this article.

\section{References}

1. Lisboa Bastos M, Tavaziva G, Abidi SK, Campbell JR, Haraoui LP, Johnston JC, et al. Diagnostic accuracy of serological tests for covid-19: systematic review and meta-analysis. BMJ. 2020; 370: m2516. doi: 10.1136/bmj.m2516. 
2. Damluji AA, Christenson RH, deFilippi C. Clinical Application of Serologic Testing for Coronavirus Disease 2019 in Contemporary Cardiovascular Practice. J Am Heart Assoc. 2021; 10 (5) : e019506. doi: 10.1161/JAHA.120.019506.

3. Guo L, Ren L, Yang S, Xiao M, Chang D, Yang F, et al. Profiling Early Humoral Response to Diagnose Novel Coronavirus Disease (COVID-19). Clin Infect Dis. 2020; 71 (15): 778-785. doi: 10.1093/cid/ciaa310.

4. Zhao J, Yuan Q, Wang H, Liu W, Liao X, Su Y, et al. Antibody Responses to SARS-CoV-2 in Patients With Novel Coronavirus Disease 2019. Clin Infect Dis. 2020; 71 (16): 2027-2034. doi: $10.1093 / \mathrm{cid} / \mathrm{ciaa344}$.

5. Theel ES, Slev P, Wheeler S, Couturier MR, Wong SJ, Kadkhoda K. The Role of Antibody Testing for SARS-CoV-2: Is There One? J Clin Microbiol. 2020; 58 (8): e00797-20. doi: 10.1128/JCM.00797-20.

6. Dortet L, Ronat JB, Vauloup-Fellous C, Langendorf C, Mendels DA, Emeraud C, et al. Evaluating 10 Commercially Available SARS-CoV-2 Rapid Serological Tests by Use of the STARD (Standards for Reporting of Diagnostic Accuracy Studies) Method. J Clin Microbiol. 2021; 59(2): e02342-20. doi: 10.1128/JCM.02342-20.

7. Cota G, Freire ML, de Souza CS, Pedras MJ, Saliba JW, Faria V, et al. Diagnostic performance of commercially available COVID-19 serology tests in Brazil. Int J Infect Dis. 2020; 101: 382-390. doi: 10.1016/j.ijid.2020.10.008.

8. Zhang R,Li J. Reasons and solutions for "false positive results" of 2019 Novel Coronavirus-specific antibodies detection. Chin J Lab Med. 2020; 43 (00): E020.

9. Geneva: World Health Organization. WHO Guidelines for malaria. 2021. PMID: 33724744.

10. Wang Q, Du Q, Guo B, Mu D, Lu X, Ma Q, et al. A Method To Prevent SARS-CoV-2 IgM False Positives in Gold Immunochromatography and Enzyme-Linked Immunosorbent Assays. J Clin Microbiol. 2020; 58 (6): e00375-20. doi: 10.1128/JCM.00375-20.

11. Yadouleton A, Sander AL, Moreira-Soto A, Tchibozo C, Hounkanrin G, Badou Y, et al. Limited Specificity of Serologic Tests for SARS-CoV-2 Antibody Detection, Benin. Emerg Infect Dis. 2021; 27 (1): 233-7. doi: 10.3201/eid2701.203281.

\section{Figures}




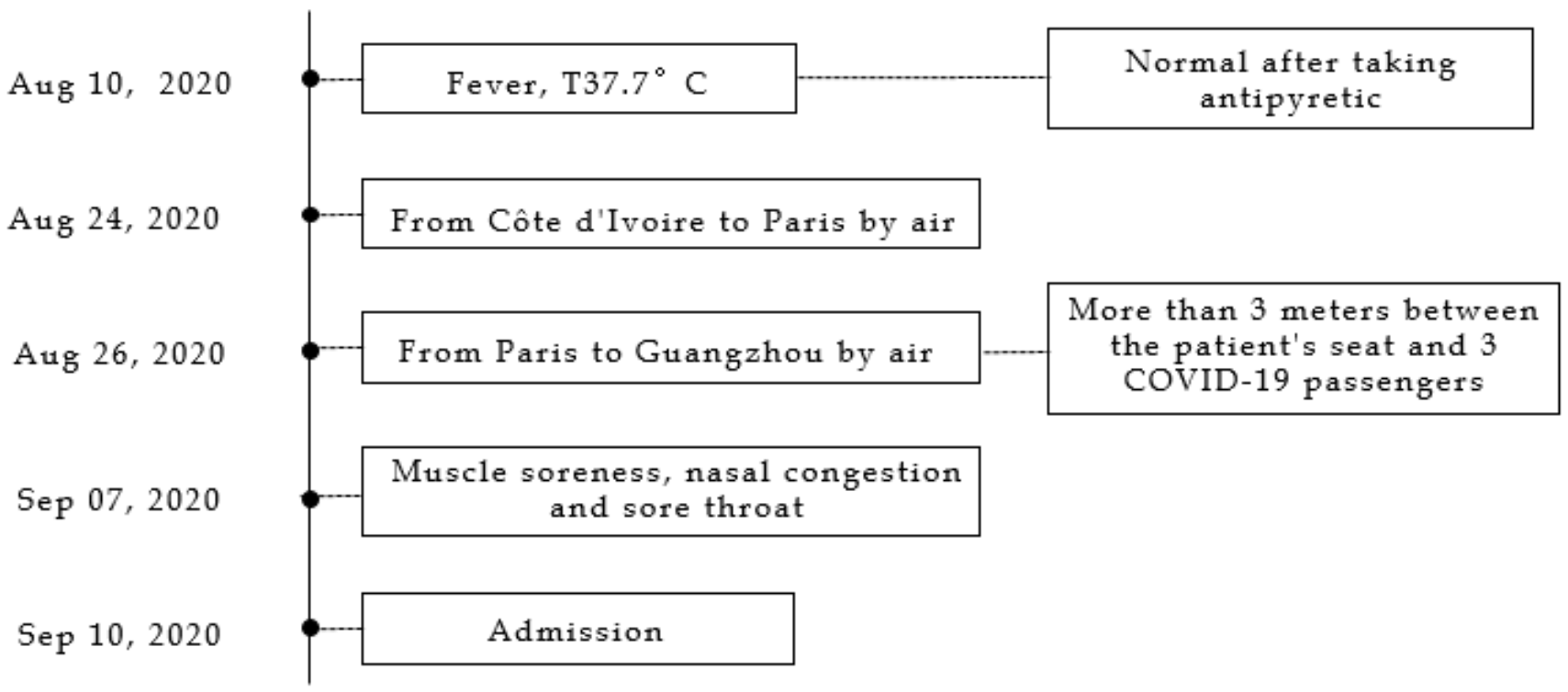

\section{Figure 1}

Timeline of suspicious exposure to COVID-19 and symptom

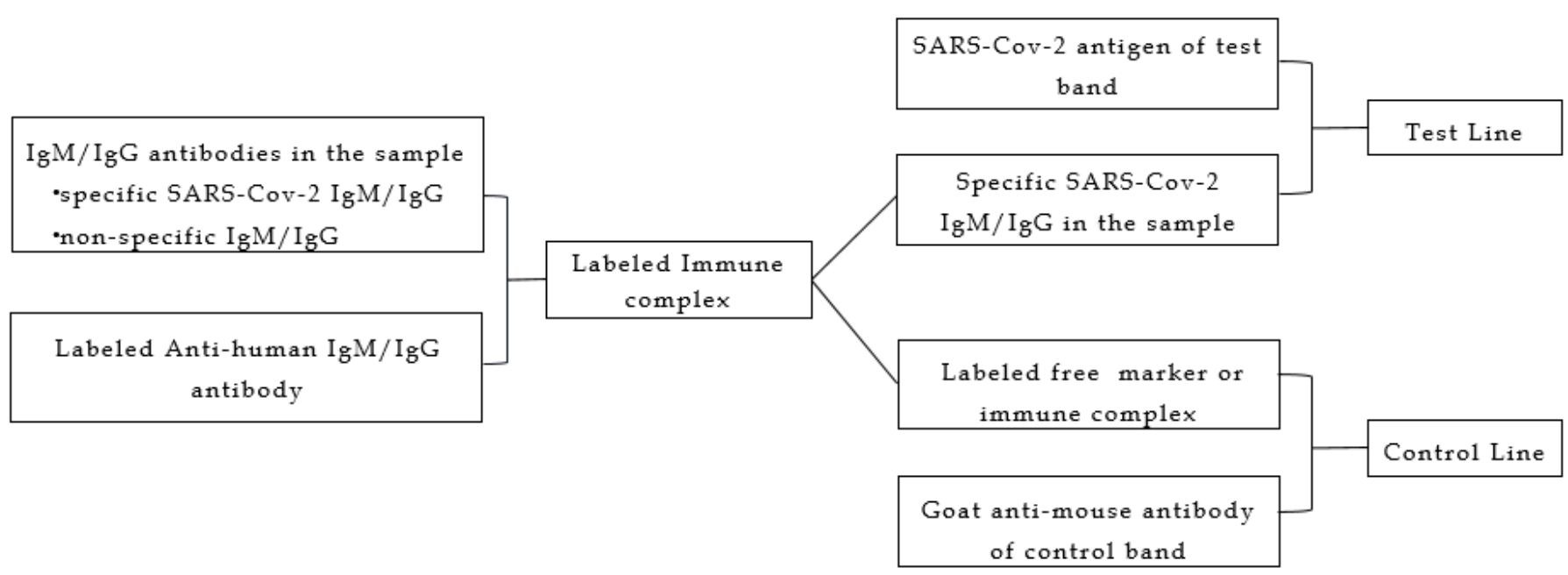

\section{Figure 2}

Principle of SARS-Cov-2 lgM/lgG antibody-detecting rapid diagnostic tests Note: SARS-Cov-2 rapid diagnostic test is a lateral flow immunochromatographic device that detects antibody. It has two cards test device (IgM and IgG cards). A sample of blood including lgM or lgG antibody is mixed with labeled Ab (Anti-human IgM/lgG antibody). Specific SARS-Cov-2 IgM/lgG antibody is captured by SARS-Cov-2 antigen and trapped on the test line. Other labeled antibody is trapped on the control line. 

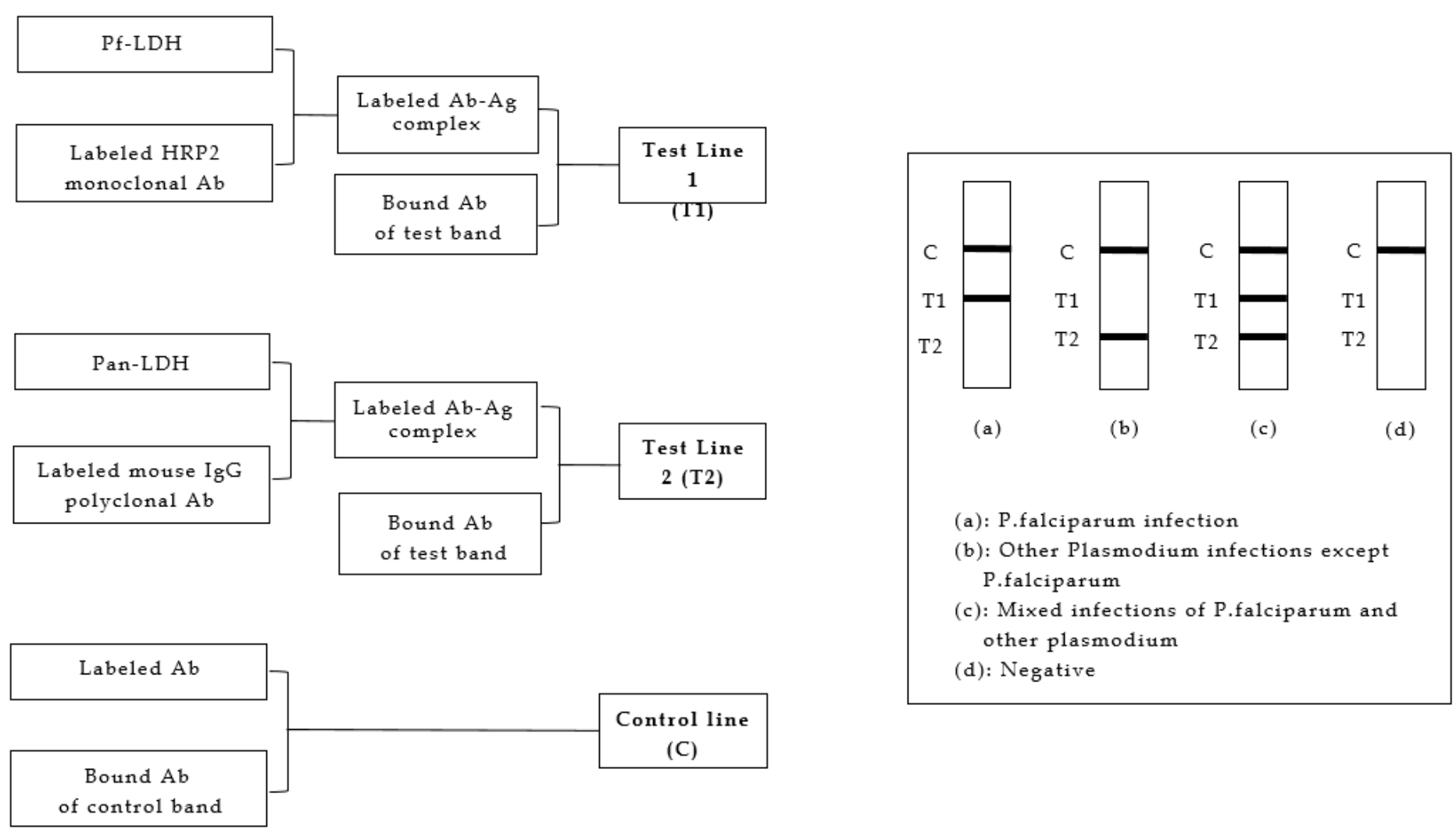

Figure 3

Principle of malaria antigen-detecting rapid diagnostic tests Note: Pf-LDH, plasmodium falciparum lactate dehydrogenase; Pan-LDH, plasmodium lactate dehydrogenase; Ab, antibody; Ag, antigen. Malaria rapid diagnostic test (RDT) is a lateral flow immunochromatographic device that detects protein (antigen [Ag]). A sample of blood is placed on the RDT strip, and lysed to release the Ag from within red blood cells and parasites from within these cells. After several minutes, the test produces a series of visible lines to signal the presence or absence of $\mathrm{Ag}$ in the blood sample. Plasmodium falciparum lactate dehydrogenase (Pf-LDH) binding to labeled antibody ( $\mathrm{Ab}$ ) is trapped on the test line 1 (T1). Plasmodium lactate dehydrogenase (Pan-LDH) binding to labeled antibody is trapped on the test line 2 (T2). RDT may identify plasmodium or may distinguish P. falciparum and/or other plasmodium infections. T1 positive, P. falciparum infection; T2 positive, other plasmodium infections (P. vivax, P. ovale, P. malariae) except P. falciparum; T1 and T2 positive, mixed infections of $P$. falciparum and other plasmodium. 